\title{
Canary Islands cardiologists' attitudes toward alcohol and cardiovascular health
}

\author{
Actitudes de los cardiólogos de Islas Canarias sobre el alcohol y la salud cardiovascular
}

Sohaib Haseeb ${ }^{1}$, Juan Lacalzada-Almeida², Antonio Barragan², Ricardo López-Sant ${ }^{3}$, Alejandro Cuesta ${ }^{4}$, and Adrian Baranchuk ${ }^{5}$

${ }^{1}$ College of Medicine and Dentistry, James Cook University, Townsville, Queensland, Australia; ${ }^{2}$ Department of Cardiology, Hospital Universitario de Canarias, Tenerife, Spain; ${ }^{3}$ Cardiology Service, Hospital Italiano de La Plata, Buenos Aires, Argentina; ${ }^{4}$ Cardiology Service, Centro Cardiovascular Universitario, Hospital de Clínicas, Montevideo, Uruguay; ${ }^{5}$ Division of Cardiology, Queen's University, Kingston, Ontario, Canada

Alcohol consumption constitutes a major part of Western culture ${ }^{1}$. The World Health Organization estimated that alcohol is consumed by more than half of the population in the Americas, Europe, and the West Pacific ${ }^{2}$. Although the adverse effects of alcohol abuse related to physical, mental, and specifically cardiovascular health are well-established, the cardiovascular nature of controlled, light-to-moderate intake remains a topic of debate in the literature. At present, there are limited data on the knowledge of health-care practitioners as it relates to alcohol and its effects on cardiovascular health, and it is limited to the region of Latin America ${ }^{3,4}$. Given that cardiologists are in a position to counsel patients regarding alcohol intake, we sought to evaluate self-reported attitudes and recommendations of cardiologists residing in the Canary Islands toward the effects of alcohol on cardiovascular health and to establish their sources of knowledge.

We conducted a web-based cross-sectional survey of attending cardiologists and advanced cardiology trainees through a Google Forms (Mountain View, California) link that was distributed through the Canary Society of Cardiology, which endorsed this study. Respondents were anonymously surveyed about their demographics, perceptions on alcohol and cardiovascular health, and their knowledge and understanding of drinking guidelines. Questions were derived from our previously conducted surveys in Argentina ${ }^{3}$ and Uruguay $^{4}$, and the responses of these Latin American countries are compared with the Canary Islands in the present analysis. Data were analyzed using the Pearson Chi-squared test or Fisher's exact and Mann-Whitney U-tests as appropriate, with two-tailed $p<0.05$ considered to be statistically significant.

The survey was conducted between January 6, 2019, and February 16, 2019, with 79 of 115 (69\%) cardiologists in the Canary Islands responding. Among these, 69 were attending cardiologists and 10 were advanced cardiology trainees. The majority of respondents were male $(67 \% ; 53 / 79)$, and $87 \%$ (69/79) worked in an academic setting. The characteristics of the study population are described in Table 1 with comparison to Latin American cardiologists (response rate 54\%) from Argentina $(n=745)$ and Uruguay $(n=298)$. Overall, respondents from the Canary Islands showed a mixed view regarding the appropriateness of drinking alcohol as it relates to cardiovascular health benefits: $38 \%(30 / 79)$ viewed alcohol to be beneficial in moderation, $37 \%$ (29/79) viewed any intake of alcohol to be harmful, $20 \%$ $(16 / 79)$ viewed only wine to be beneficial, and 5\% (4/79)

\section{Correspondence:}

*Adrian Baranchuk

E-mail: adrian.baranchuk@kingstonhsc.ca
Available online: $15-10-2020$ Arch Cardiol Mex. 2020;90(4):496-499 www.archivoscardiologia.com 2604-7063 / @ 2020 Instituto Nacional de Cardiología Ignacio Chávez. Published by Permanyer. This is an open access article under the CC BY-NC-ND license (http://creativecommons.org/licenses/by-nc-nd/4.0/). 
Table 1. Population characteristics with region-specific comparison between the Canary Islands and Latin America

\begin{tabular}{|c|c|c|c|c|}
\hline \multirow[t]{2}{*}{ Variable } & \multirow{2}{*}{$\begin{array}{l}\text { All } \\
\text { respondents* } \\
(\mathrm{n}=1122)\end{array}$} & \multicolumn{2}{|c|}{ Respondent group } & \multirow[t]{2}{*}{ p-value } \\
\hline & & $\begin{array}{l}\text { Canary } \\
\text { Islands } \\
(\mathbf{n}=79)\end{array}$ & $\begin{array}{c}\text { Latin } \\
\text { America** } \\
\text { (n = 1043) }\end{array}$ & \\
\hline $\begin{array}{l}\text { Age, } \mathrm{n}(\%) \\
<35 \text { years } \\
35-44 \text { years } \\
45-54 \text { years } \\
55-64 \text { years } \\
>65 \text { years }\end{array}$ & $\begin{array}{l}197(18) \\
294(27) \\
279(25) \\
237(21) \\
102(9)\end{array}$ & $\begin{array}{c}33(42) \\
26(33) \\
8(10) \\
8(10) \\
4(5)\end{array}$ & $\begin{array}{l}164(16) \\
268(26) \\
271(26) \\
229(22) \\
98(10)\end{array}$ & $<0.001$ \\
\hline $\begin{array}{l}\text { Gender, } n(\%) \\
\text { Male } \\
\text { Female }\end{array}$ & $\begin{array}{l}725(65) \\
393(35)\end{array}$ & $\begin{array}{l}53(67) \\
26(33)\end{array}$ & $\begin{array}{l}672(65) \\
367(35)\end{array}$ & 0.665 \\
\hline $\begin{array}{l}\text { Clinical practice setting, } \mathrm{n}(\%) \\
\text { Urban or rural } \\
\text { Urban } \\
\text { Rural } \\
\text { Both }\end{array}$ & $\begin{array}{c}1083(96) \\
5(1) \\
32(3)\end{array}$ & $\begin{array}{c}79(100) \\
0(0) \\
0(0)\end{array}$ & $\begin{array}{c}1004(96) \\
5(1) \\
32(3)\end{array}$ & 0.234 \\
\hline $\begin{array}{l}\text { Academic or non-academic } \\
\text { University hospital (A) } \\
\text { Private academic (A) } \\
\text { Private hospital (NA) } \\
\text { Private clinic (NA) } \\
\text { Community hospital (NA) } \\
\text { Other (NA) }\end{array}$ & $\begin{array}{l}301(27) \\
13(1) \\
431(38) \\
245(22) \\
118(11) \\
10(1)\end{array}$ & $\begin{array}{l}69(87) \\
0(0) \\
3(4) \\
2(3) \\
5(6) \\
0(0)\end{array}$ & $\begin{aligned} 232(22) \\
13(1) \\
428(41) \\
243(24) \\
113(11) \\
10(1)\end{aligned}$ & $<0.001$ \\
\hline $\begin{array}{l}\text { Perceptions on alcohol and cardiovascular health, } \mathrm{n}(\%) \\
\text { Alcohol beneficial in moderation } \\
\text { Alcohol beneficial at any level } \\
\text { Any intake of alcohol harmful } \\
\text { Only wine beneficial } \\
\text { Other opinions }\end{array}$ & $\begin{array}{l}386(35) \\
1(0) \\
314(28) \\
361(33) \\
48(4)\end{array}$ & $\begin{aligned} 30 & (38) \\
0 & (0) \\
29 & (37) \\
16 & (20) \\
4 & (5)\end{aligned}$ & $\begin{array}{l}356(35) \\
1(0) \\
285(28) \\
345(33) \\
44(4)\end{array}$ & 0.165 \\
\hline $\begin{array}{l}\text { Knowledge of drinking guidelines } \\
\text { Satisfaction with own knowledge, mean } \pm S D^{\Uparrow} \\
\text { Satisfaction in counseling patients, mean } \pm S D^{\Uparrow} \\
\text { Are drinking guidelines well known to health-care practitioners, n (\%) } \\
\text { Yes } \\
\text { No } \\
\text { Other }\end{array}$ & $\begin{array}{l}2.83 \pm 2.69 \\
5.97 \pm 3.15 \\
\\
22(2) \\
676(60) \\
422(38)\end{array}$ & $\begin{array}{r}2.66 \pm 2.39 \\
5.56 \pm 2.70 \\
1(1) \\
51(65) \\
27(34)\end{array}$ & $\begin{array}{l}2.84 \pm 2.71 \\
6.01 \pm 3.18 \\
21(2) \\
625(60) \\
395(38)\end{array}$ & $\begin{array}{l}0.561 \\
0.164 \\
0.804\end{array}$ \\
\hline $\begin{array}{l}\text { Should drinking guidelines be standardized across countries, } \mathrm{n}(\%) \\
\text { Yes } \\
\text { No } \\
\text { Other }\end{array}$ & $\begin{array}{c}948(87) \\
111(10) \\
37(3)\end{array}$ & $\begin{array}{c}73(93) \\
5(6) \\
1(1)\end{array}$ & $\begin{array}{c}875(86) \\
106(10) \\
36(4)\end{array}$ & 0.257 \\
\hline $\begin{array}{l}\text { Knowledge of drinking metric units } \\
\text { Awareness of metric "standard drink", } \mathrm{n}(\%) \\
\text { Yes } \\
\text { No } \\
\text { Maybe } \\
\text { Satisfaction in converting "standard drink" to other metric units, mean } \pm \mathrm{SD}^{\text {" }}\end{array}$ & $\begin{array}{c}473(42) \\
509(46) \\
134(12) \\
1.84 \pm 2.58\end{array}$ & $\begin{array}{c}48(61) \\
22(28) \\
9(11) \\
2.09 \pm 2.48\end{array}$ & $\begin{array}{c}425(41) \\
487(47) \\
125(12) \\
1.82 \pm 2.59\end{array}$ & 0.002 \\
\hline $\begin{array}{l}\text { Should alcohol consumption be reported in forms other than "standard drink," } \mathrm{n}(\%) \\
\text { Yes } \\
\text { No } \\
\text { Other }\end{array}$ & $\begin{array}{c}937(84) \\
65(6) \\
116(10)\end{array}$ & $\begin{array}{c}76(96) \\
1(1) \\
2(3)\end{array}$ & $\begin{array}{c}861(83) \\
64(6) \\
114(11)\end{array}$ & 0.008 \\
\hline
\end{tabular}

Bold defines $p<0.05$.

*The survey was administered in a non-forced manner and respondents were permitted to leave questions blank; therefore, cell counts may not always equal the sample size because of small amounts of missing data for age $(n=13)$, gender $(n=4)$, urban or rural practice setting $(n=2)$, academic or non-academic practice setting $(n=4)$, perceptions on alcohol and cardiovascular health $(n=12)$, satisfaction with own knowledge $(n=7)$, satisfaction in counseling patients $(n=7)$, drinking guidelines be standardized across countries $(n=26)$, drinking guidelines well known to health-care practitioners $(n=2)$, awareness of metric "standard drink" ( $n=6)$, satisfaction in converting "standard drink" to other metric units $(n=20)$, alcohol consumption be reported in forms other than "standard drink" $(n=4)$.

** Latin America is a generalized term to encompass responses from Argentina $(n=745)$ and Uruguay $(n=298)$.

१This survey question was administered on a Likert scale defined as: $0=$ not satisfied to $10=$ extremely satisfied.

had other opinions. Respondents from both the Canary Islands and Latin America held similarly mixed views $(p=0.165)$ on this topic (Table 1). Furthermore, our survey showed that respondents from the Canary Islands were not satisfied with their self-reported knowledge of drinking guidelines $(0=$ not satisfied, 


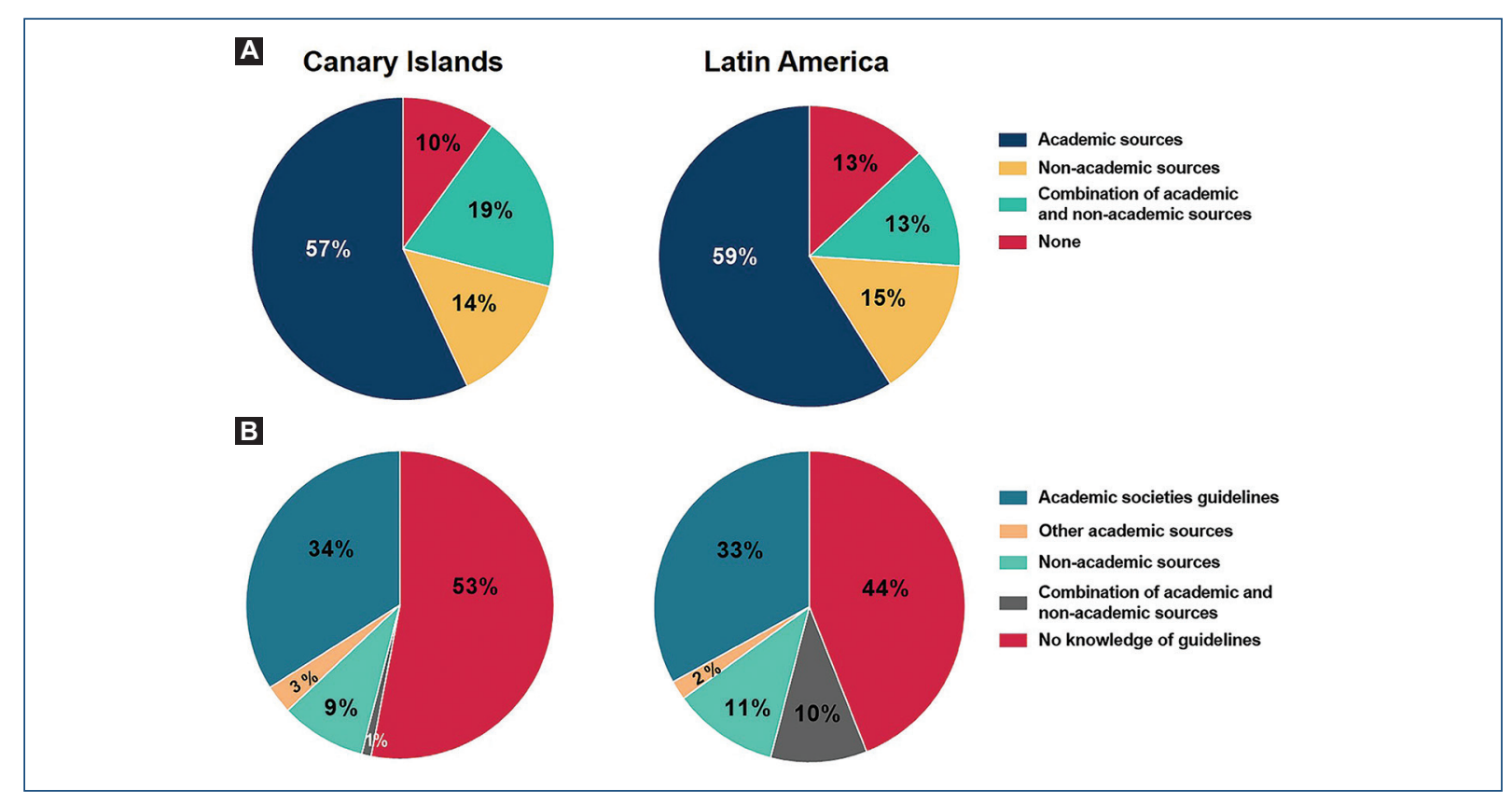

Figure 1. Region-specific comparison of self-reported sources of knowledge on A: alcohol and cardiovascular health and $\mathbf{B}$ : drinking guidelines.

$10=$ extremely satisfied $)(2.66 \pm 2.39)$. There were no significant differences in response between the Canary Islands and Latin American respondents $(p=0.561)$. Despite this, respondents from the Canary Islands reported that they were relatively comfortable in counseling patients regarding the safe limits of alcohol consumption $(5.56 \pm 2.70)$, similar to the Latin American $(6.01 \pm 3.18)$ respondents $(p=0.164)$. Concerning the knowledge of drinking metrics, particularly "standard drink" (SD), $61 \%$ (48/79) of the Canary Islands respondents were aware of the concept, but they were largely not comfortable in converting SD to other metric units $(2.09 \pm 2.48)$. More than half $(65 \% ; 51 / 79)$ believed that drinking guidelines were not well known to healthcare practitioners, and 93\% (73/79) preferred drinking guidelines to be standardized across countries. Region-specific comparison of responses regarding knowledge of drinking metrics and guidelines is summarized in table 1. Notably, there were many academic and non-academic sources from which respondents obtained their knowledge on this topic among both regions (Fig. 1).

Our findings suggest that there are opportunities for targeted promotion and education at both the individual and systems levels of health care on the benefits and detriments of alcohol as it relates to cardiovascular health. The relationship between alcohol and health remains complex, and it is influenced by culture, religion, health context, and societal trends. Evidence from a subanalysis of an internet-based, longitudinal, cardiovascular cohort study suggested that the vast majority of lay participants who viewed alcohol as "heart" healthy cited the press as their source of knowledge ${ }^{5}$. Given the considerable equipoise on the issue of alcohol and cardiovascular health, it is important to understand the attitudes of our health-care practitioners as they may play a role in medical advice. Our survey found that the knowledge and understanding of drinking guidelines among cardiologists from the Canary Islands and Latin America are low. Drinking guidelines have been defined in at least 37 countries $^{1}$, and there are cross-national variations in the consumption limits, SD metrics, and low-risk thresholds. These discrepancies have the potential to inappropriately influence behavior, and therefore, drinking guidelines that define clear thresholds should be discussed in training in a proactive manner.

Our study is limited by its cross-sectional design and reliance on self-reported data. Furthermore, the sample size of the Canary Islands population was limited $(n=79)$. This small sample size reduces the statistical power of the comparisons made between the two geographical areas of interest. Although the two respondent groups had similar perceptions, it is important to highlight the differences between the cardiologists residing in the Canary Islands and in Latin America, mainly in age and academic versus non-academic workplace setting. Another limitation is that responses 
from cardiologists from the Canary Islands do not represent (necessarily) the view of the Spaniard cardiologists from continental Spain.

Our survey demonstrates the considerable variability in the perceptions and sources of knowledge of cardiologists concerning alcohol and its effects on cardiovascular health. Future work should address how these patterns in attitudes compare between North American and continental European health-care practitioners.

\section{Acknowledgements}

The authors would like to acknowledge Drs. Pablo Jorge and Antonio García Quintana for their support in the recruitment and distribution of surveys.

\section{Funding}

This research has not received any specific grant from public, commercial, or non-profit agencies.

\section{Conflicts of interest}

None.

\section{Ethical disclosures}

Protection of human and animal subjects. The authors declare that the procedures followed were in accordance with the regulations of the relevant clinical research ethics committee and with those of the Code of Ethics of the World Medical Association (Declaration of Helsinki).

Confidentiality of data. The authors declare that no patient data appear in this article.

Right to privacy and informed consent. The authors declare that no patient data appear in this article.

\section{References}

1. Haseeb S, Alexander B, Baranchuk A. Wine and cardiovascular health: a comprehensive review. Circulation. 2017;136:1434-48.

2. World Health Organisation. Global Status Report on Alcohol and Health 2018. Geneva: World Health Organization; 2018. Available from: https:// www.apps.who.int/iris/handle/10665/274603.

3. Santi RL, Haseeb S, Alexander B, D'Ovidio A, Gimenez S, Secotaro C, et al. Attitudes and recommendations of physicians towards alcohol consumption and cardiovascular health: a perspective from Argentina. Diseases. 2018:6:77.

4. Cuesta A, Haseeb S, Aquistapache F, Grosso P, Alexander B, Hopman W, et al. Alcohol consumption and cardiovascular health: a nationwide survey of Uruguayan cardiologists. Alcohol. 2019;79:163-9.

5. Whitman IR, Pletcher MJ, Vittinghoff E, Imburgia KE, Maguire C, Bettencourt $L$, et al. Perceptions, information sources, and behavior regarding alcohol and heart health. Am J Cardiol. 2015;116:642-6. 